\title{
Oral corticosteroids for wheezing attacks under 18 months
}

\author{
M S C WEBB, R L HENRY, AND A D MILNER \\ Department of Child Health, Queen's Medical Centre, Nottingham
}

SUMMARY In a double blind, partial crossover trial we compared treatment with prednisolone with treatment with placebo (56 treatments) in 38 children aged less than 18 months (mean age 9.8 months, range 3-17 months), 30 of whom had required previous admission to hospital. Placebo or oral prednisolone $2 \mathrm{mg} / \mathrm{kg} /$ day in two divided doses for five days was given during acute exacerbations of symptoms on an outpatient basis. Daily symptom scores of cough, wheeze, and breathlessness did not show any significant difference in rate of improvement or overall outcome, either between the two whole groups or within subgroups aged less than 6 months, 6-12 months, and 12-18 months. Parental preference failed to indicate superiority of treatment with prednisolone over treatment with placebo in the 18 crossover patients, and parents were equally as likely to feel that treatment with either placebo or prednisolone had had positive effect in non-crossover patients. Two children required admission to hospital during treatment, one aged $51 / 2$ months being treated with prednisolone, and one aged 14 months being treated with placebo.

Recurrent wheezing attacks in children aged under 18 months are a considerable source of morbidity and a not uncommon cause for admission to hospital. Although the list of differential diagnoses is lengthy and includes conditions such as cystic fibrosis, aspiration syndrome, and foreign body, most of these children are suffering from asthma. The clear benefit to the patient after appropriate treatment with anti-asthma drugs consequent on correct diagnostic labelling has been shown by Speight et al. ${ }^{1}$ Sadly, this does not necessarily hold true for very young children due to their variable and often non-existent responsiveness to treatment with bronchodilators. ${ }^{2}$ Although the mechanisms underlying this limited responsiveness are by no means fully understood, one of the suggestions has been that the pathology is primarily that of inflammation, with mucosal oedema and inflammatory exudate being principal features, none of which would be susceptible to specific bronchodilators. This fact, coupled with the extreme paucity of published information on the role of corticosteroids in the age group 0-18 months, prompted us to assess what part corticosteroids might have to play in the management of this difficult clinical problem.

\section{Patients and methods}

Thirty eight children aged less than 18 months were studied. There were 28 boys and 10 girls. All had suffered at least two previous attacks of wheezing, and in none was any diagnosis other than asthma under active consideration. In an attempt to avoid treating trivial and rapidly self limiting episodes only those attacks that had lasted at least 48 hours and were still of sufficient severity to merit therapeutic intervention on standard clinical criteria were included. Minimum requirements were persistent wheezing and/or coughing, associated with tachypnoea, subcostal recession, and rhonchi on examination, these symptoms being sufficiently troublesome to cause some disturbance to feeding and sleeping. Any child requiring immediate admission to hospital was excluded. Patients were enrolled into the study after self referral to our unit by the parents, initial contact having been made in the outpatient department or during a previous hospital admission for asthma.

Patients were randomly allocated to treatment with either placebo or soluble prednisolone $1 \cdot 0$ $\mathrm{mg} / \mathrm{kg}$ twice daily for five days on a double blind 
basis. Crossover was completed either if a child had showed no improvement eight days after beginning treatment-that is, three days after finishing treatment - or if they presented with a subsequent attack at a later date. If treatments, such as bronchodilator or antibiotics had already been begun by the general practitioner they were continued.

Parents were asked to maintain a diary record at home during the course of treatment and for the subsequent three days. Scores of 0 to $3(0=$ no symptoms, $1=$ 'a bit', $2=$ 'quite bad', $3=$ 'very bad') were recorded for each of cough, wheeze, and breathlessness/difficulty in breathing for both day and night, giving a possible maximum total for each 24 hours of 18 . Patients were reviewed at eight days, and at that time parents were asked whether or not they considered that the treatment had in any way altered the course of the attack compared with previous similar (untreated) attacks.

Statistical analysis employed the $\chi^{2}$ test, Fisher's exact test, and Mann-Whitney U test where appropriate. Statistical validity of the results was estimated using the sample size and power estimations described by Fleiss. ${ }^{3}$

Informed consent was obtained from the parents before entry into the trial. The study was approved by the local ethical committee.

\section{Results}

Thirty eight children were given a total of 56 treatment courses ( 18 crossover patients), 29 prednisolone and 27 placebo. There were no significant differences between the groups with respect to age, sex, age at onset of first symptoms, number of previous admissions to hospital for asthma, or length of attack before starting treatment (Table 1).
Table 1 Patient details (no of patients $=38$; no of treatment courses $=56$ )

\begin{tabular}{|c|c|c|c|}
\hline & & $\begin{array}{l}\text { Group treated } \\
\text { with prednisolone } \\
(n=29)\end{array}$ & $\begin{array}{l}\text { Group treated } \\
\text { with placebo } \\
(n=27)\end{array}$ \\
\hline $\begin{array}{l}\text { Age at study } \\
\text { (months) }\end{array}$ & $\begin{array}{c}\text { (mean }(\mathrm{SD}) \\
\text { range) }\end{array}$ & $\begin{array}{l}10 \cdot 4(4 \cdot 1) \\
3 \cdot 5-17\end{array}$ & $\begin{array}{l}9.3(3.7) \\
3.2-15 \cdot 7\end{array}$ \\
\hline Sex & $(\mathrm{M}: \mathrm{F})$ & $19: 10$ & $21: 6$ \\
\hline $\begin{array}{l}\text { Age at onset } \\
\text { (months) }\end{array}$ & $\begin{array}{l}\text { (mean }(\mathrm{SD}) \\
\text { range) }\end{array}$ & $\begin{array}{l}3 \cdot 5(3 \cdot 1) \\
0-12\end{array}$ & $\begin{array}{l}3 \cdot 4(2 \cdot 7) \\
0-11\end{array}$ \\
\hline $\begin{array}{l}\text { Previous admissions: } \\
\text { No }(\%) \text { of patient } \\
\text { No of admissions }\end{array}$ & $\mathbf{s} \geqslant 1$ & $\begin{array}{l}21(72 \%) \\
30\end{array}$ & $\begin{array}{l}21(78 \%) \\
34\end{array}$ \\
\hline $\begin{array}{l}\text { Length of attack } \\
\text { before treatment } \\
\text { (days) }\end{array}$ & $\begin{array}{l}\text { (mean (SD) } \\
\text { range) }\end{array}$ & $\begin{array}{l}8 \cdot 0(5 \cdot 6) \\
2-21\end{array}$ & $\begin{array}{l}7 \cdot 3(5 \cdot 8) \\
2-21\end{array}$ \\
\hline
\end{tabular}

There were also no differences in personal history of eczema or family history of asthma, eczema, or hay fever. Three of the group given prednisolone had been prescribed bronchodilators by their general practitioner at the onset of the attack compared with five in the group given placebo; a further two in the group given placebo had been given antibiotics.

The severity of the attacks was similar in the two groups at the time of beginning treatment, there being no difference in scores on day 1 (median of group given prednisolone $=9$, median of group given placebo $=9.5 ; p=0.64$ by Mann-Whitney test). Neither was there any difference between the groups' scores on days 3,5 , and 7 (Table 2), however, suggesting similar progress through and outcome of the courses of treatment.

Figures 1-3 present data from all the patients studied. Analysis of these data by comparing the number of positive and negative changes over the intervals day 1 to day 3 , day 1 to day 5 , and day 1 to day 7 showed no significant difference between treatment with prednisolone and placebo in the

Table 2 Median values of symptom score on days 1, 3, 5, and 7

\begin{tabular}{|c|c|c|c|c|c|}
\hline \multirow[t]{2}{*}{ Patients' age group } & \multirow[t]{2}{*}{ Treatment } & \multicolumn{4}{|c|}{ Median score } \\
\hline & & Day 1 & Day 3 & Day 5 & Day 7 \\
\hline $0-18$ months $(n=38)$ & $\begin{array}{l}\text { Prednisolone }(n=29) \\
\text { Placebo }(n=26)^{\dagger}\end{array}$ & $\begin{array}{l}9 \\
9 \cdot 5\end{array}$ & $\begin{array}{l}8 \\
9\end{array}$ & $\begin{array}{l}7 \\
5 \cdot 5\end{array}$ & $\begin{array}{l}5 \\
6\end{array}$ \\
\hline $0-6$ months $(\mathrm{n}=10)^{*}$ & $\begin{array}{l}\text { Prednisolone }(n=6) \\
\text { Placebo }(n=6)\end{array}$ & $\begin{array}{l}8 \cdot 5 \\
8\end{array}$ & $\begin{array}{l}9 \cdot 5 \\
11 \cdot 5\end{array}$ & $\begin{array}{l}9 \\
9\end{array}$ & $\begin{array}{l}7 \\
10\end{array}$ \\
\hline $6-12$ months $(n=17)^{*}$ & $\begin{array}{l}\text { Prednisolone }(n=13) \\
\text { Placebo }(n=14)\end{array}$ & $\begin{array}{l}9 \\
9 \cdot 5\end{array}$ & $\begin{array}{l}8 \\
8 \cdot 5\end{array}$ & $\begin{array}{l}5 \\
4\end{array}$ & $\begin{array}{l}4 \\
3 \cdot 5\end{array}$ \\
\hline $12-18$ months $(n=11)$ & $\begin{array}{l}\text { Prednisolone }(n=10) \\
\text { Placebo }(n=6) \dagger\end{array}$ & $\begin{array}{l}10 \\
11 \cdot 5\end{array}$ & $\begin{array}{l}8 \\
10 \cdot 5\end{array}$ & $\begin{array}{l}6 \cdot 5 \\
7\end{array}$ & $\begin{array}{l}4 \cdot 5 \\
5\end{array}$ \\
\hline
\end{tabular}

No significant difference at $5 \%$ level between treatments (Mann-Whitney test).

* One patient had progressed to next age subgroup at the time of crossover treatment.

†One scoresheet lost by parents. 


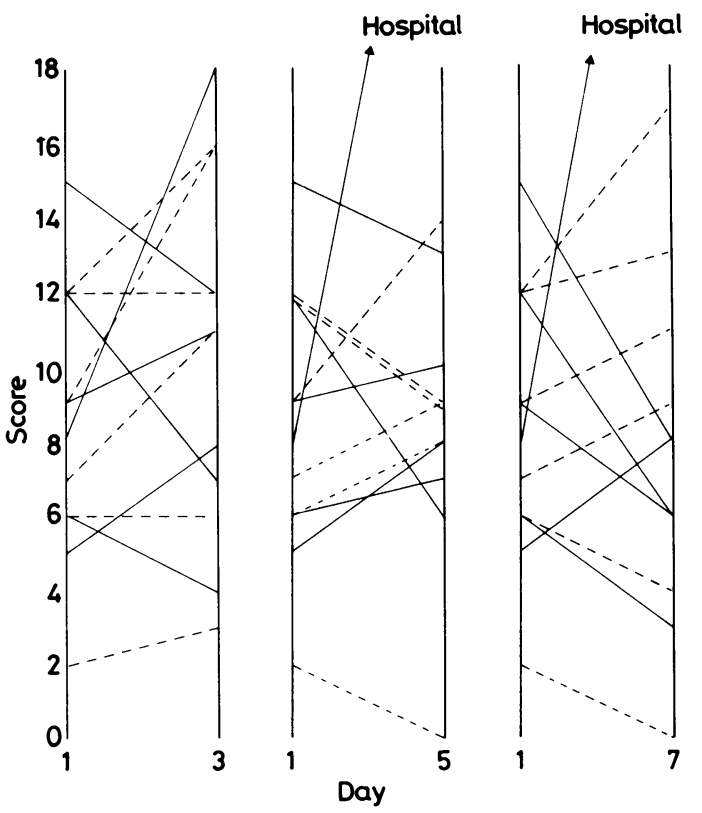

Fig. 1 Progress of individual patients, 0-6 months $(-=$ prednisolone; $----=$ placebo $)$.

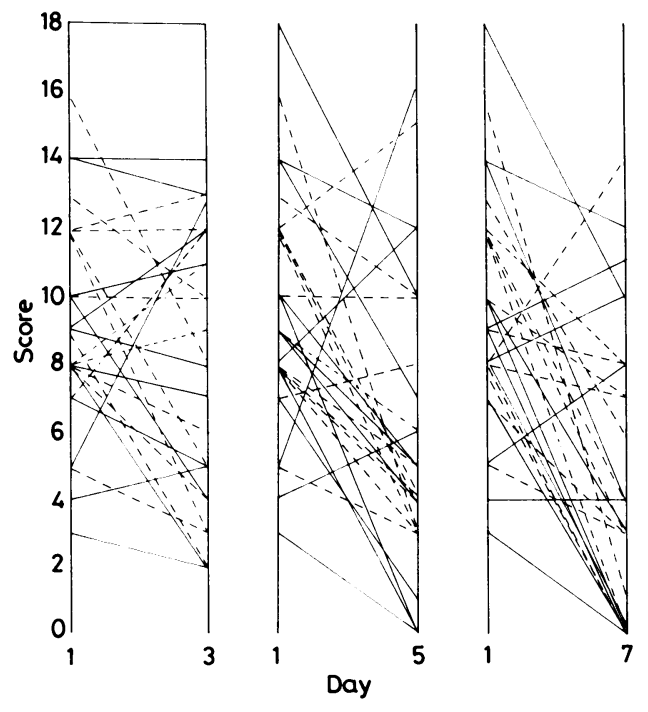

Fig. 2 Progress of individual patients, 6-12 months $(-=$ prednisolone $;----=$ placebo $)$.

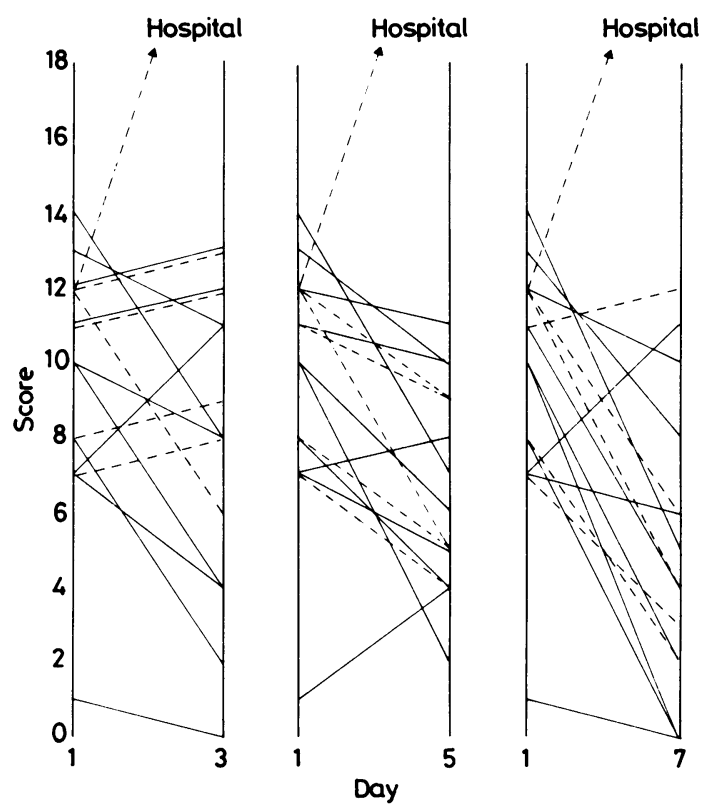

Fig. 3 Progress of individual patients, 12-18 months (one placebo not shown-'no difference whatsoever'; - = prednisolone; - - - = placebo).

whole study or within any of the age subgroups. There was, however, a trend to greater efficacy of treatment with prednisolone in the day $1-3$ period $(17 / 29(59 \%)$ of the group given prednisolone improved $v 9 / 27(33 \%)$ of the group given placebo improved; $\left.\chi^{2}=2 \cdot 65, p<0 \cdot 1\right)$, this trend being most pronounced for the 12-18 month age subgroup (7/10 $(70 \%)$ of the group given prednisolone improved $v$ $1 / 6(17 \%)$ of the group given placebo improved; $p=0.058$ by Fisher's exact test). Analysis of the median change in score over the same intervals showed no significant overall difference between the two treatments, with the trend towards earlier resolution of symptoms on treatment with prednisolone over the day 1-3 interval being less apparent (group given prednisolone median score change $-1 v$ group given placebo median score change $+0.5 ; \mathrm{p}=0.54$ by Mann-Whitney test).

Parents were unable to identify positive benefit from treatment with prednisolone over treatment with placebo. In the complete treatment groups 16 out of 29 courses of prednisolone were thought not to have benefited the child, although 12 were thought to have done so; 10 were positive and 17 were negative for placebo. Again, there was a trend towards perceived greater efficacy of treatment with 
prednisolone in the 12-18 month age group (5/9 of the group given prednisolone benefited (one 'didn't know') $v 1 / 7$ of the group given placebo benefited), but this too failed to reach significance.

If we limit our analysis to only those 18 patients who completed a full crossover trial (36 treatment courses), the two treatment groups are even less dissimilar and the trend towards earlier improvement in the older age group is lost.

In a largely negative and small clinical study it is important to make an estimate of its power. Given that the proportions of placebo courses that produced improvement over the day 1-3 period were $33 \%$ and $17 \%$ for the whole group and the $12-18$ month age subgroup, respectively, it would seem reasonable to aim for an improvement rate of three out of four $(75 \%)$ for treatment with prednisolone as indicative of a clinically acceptable benefit-this study had a $92 \%$ chance of revealing this likelihood of benefit for the whole group and an $89 \%$ chance for the 12-18 month age subgroup. The higher proportion of children who improved on treatment with placebo over the longer period of five or seven days gives the study about a $50 \%$ chance of picking up what could only be small differences over these intervals.

Two children required admission to hospital during a treatment course-one 51/2 month old boy on the fourth day of treatment with prednisolone and one boy of 14 months on the third day of treatment with placebo.

There were no side effects reported by the parents and none was detected on clinical examination at the time of review three days after completing the five day course of treatment.

\section{Discussion}

We have been unable to show consistent benefit from treatment with corticosteroids over and above treatment with placebo for moderately severe asthma attacks in children aged under 18 months.

Could it be that our method is too insensitive? Different observers (in this case different sets of parents) are bound to assess the severity of symptoms on differing scales, not least because they can only relate to the previous range of severity experienced by the individual child under observation. Therefore, to analyse total daily scores as though uniformly representative of a single scale of severity could mask minor, and possibly even quite large, differences between the groups; we were not altogether surprised to find no difference in group scores on days 1-7.

This difficulty is to a certain extent overcome by analysing the change in score between two given days (improvement $v$ no improvement) for each patient, as each statistic is then self controlled and intersubject variability is no longer a problem. With this method we are still unable to separate the progress and outcome of the two different treatment courses to a significant degree, even when restricting our analysis only to the 18 crossover patients. Our third approach was to seek parental opinion about whether or not the treatment had affected the course of the attack, a valid assessment given that most of these parents would have witnessed many similar previous attacks. Not only might they be able to report overall outcome in terms of 'dramatic improvement' or 'no change'/'deterioration', but it was also hoped that they might detect more subtle effects such as 'got better quicker than usual'-this point, though clearly very subjective, being an important possible benefit from treatment and one unlikely to be recognised by analysis of daily scores alone. Parents were just as likely, however, to feel that treatment with placebo had benefited the child as treatment with prednisolone. More importantly, over half the children that were given prednisolone were thought not to have been helped.

We do not consider that we were treating illness so trivial that we might miss a steroid response even if it were present. As a group these 38 children had suffered considerable morbidity in the past, with 30 (79\%) of them having had previous admissions to hospital with asthma. Moreover, at the time of starting treatment they had been unwell for a mean of seven to eight days and were still constitutionally upset by their symptoms. Nor do we feel that we simply undertreated with prednisolone-there are no published data on minimum dosage, but prednisolone $2 \mathrm{mg} / \mathrm{kg} /$ day for five days seems more than adequate in clinical practice with older children under similar circumstances, and there is evidence that massive doses confer no added advantage in severe attacks. ${ }^{4}$

Our small study is statistically powerful enough to have been able to pick up a theoretical improvement rate of three out of four cases after three days' treatment with prednisolone, but our results fall short of this arbitrary but desirable aim. The tendency of asthma attacks to improve over a longer period is such that this study would only have a $50 \%$ chance of identifying a small but significant advantage of treatment with prednisolone over five to seven days if it were to exist. It is pertinent, however, to note that two days after completing a five day course of treatment with prednisolone (scores on day seven) 11 out of 29 cases were still quite unwell with scores of eight or more.

Although it is almost universal practice to administer corticosteroids to patients with either 
chronic persistent or acute asthma, there is still very little documented proof of efficacy. Grant argued strongly in favour of the use of steroids in acute severe asthma in adults, ${ }^{5}$ though Luksza disputed this view. ${ }^{6}$ There is objective evidence of improvement in lung function in acute asthma in adults after infusion of hydrocortisone ${ }^{7}$ similarly, administration of both intravenous ${ }^{8}$ and oral $^{9}$ prednisolone have been shown to increase lung function in chronic asthma in adults. The few studies in children are inconclusive. Pierson et al have shown significant improvement in arterial hypoxaemia, independent of changes in ventilatory function, after intravenous infusion of betamethasone, hydrocortisone, or dexamethasone during status asthmaticus, ${ }^{10}$ but Kattan et al could show no benefit from intravenous hydrocortisone over and above bronchodilator in a similar group of children. ${ }^{11}$ Tal et al studied the effects of dexamethasone, salbutamol, and placebo, singly or in combination, on a group of wheezing infants in hospital. ${ }^{12}$ They concluded that the effects of placebo, salbutamol alone, and dexamethasone alone were essentially the same, but that salbutamol and dexamethasone together were additive and significantly better than either alone. Their numbers in each treatment group, however, were very small and included some children with an attack of acute bronchiolitis, a condition well documented as being unaffected by treatment with corticosteroids. ${ }^{13}{ }^{14}$ Despite these reservations about their study, we would agree with their findings suggesting that corticosteroids alone do not confer great advantage in the treatment of this age group as a whole, although we cannot state categorically that treatment with prednisolone did not improve some individuals. We are unable to predict which individuals these might be-of those whose parents thought that treatment with prednisolone had helped, there was no variable among age, sex, family history, length of attack, or initial severity score that differentiated them from 'nonresponders'.

In conclusion, we have been unable to show definite clinical response attributable to treatment with oral prednisolone in moderately severe asthma in children aged under 18 months. We cannot extrapolate from our data to comment on what effect corticosteroids might have in the treatment of acute severe life threatening asthma in this age group.

We thank the children and their parents and also the consultants, Professor D Hull, Dr P Barbor, Dr D Johnston, and Dr N Rutter, who allowed us to study patients under their care. Financial support was gratefully received from the Asthma Research Council.

\section{References}

' Speight ANP, Lee DA, Hey EN. Underdiagnosis and undertreatment of asthma in childhood. Br Med J 1983;286:1253-6.

2 Silverman M. Bronchodilators for wheezy infants? Arch Dis Child 1984;59:84-7.

${ }^{3}$ Fleiss JL. Determining sample scores needed to detect a difference between two proportions. In: Bradley RA. Hunter JJ, Kendall DG, Watson GS. Probability and Mathematical Studies. Statistical methods for rates and proportions. New York: John Wiley and Sons, 1973:28-33.

${ }^{4}$ Harfi H, Hannissian AS, Crawford LV. Treatment of status asthmaticus in children with high doses and conventional doses of methylprednisolone. Pediatrics 1978;61:829-31.

5 Grant IWB. Are corticosteroids necessary in the treatment of severe acute asthma? Br J Dis Chest 1982;76:125-9.

${ }^{6}$ Luksza AR. Acute severe asthma treated without steroids. Br J Dis Chest 1982;76:15-9.

7 Fanta CH, Rossing TH, McFadden ER, Jr. Glucocorticoids in acute asthma. A critical controlled trial. Am Rev Respir Dis 1982;125:94.

${ }^{8}$ Ellul-Micallef R, Fenech FF. Intravenous prednisolone in chronic bronchial asthma. Thorax 1975;30:312-5.

${ }^{9}$ Ellul-Micallef R, Borthwick RC, McHardy GJR. The time course of response to prednisolone in chronic bronchial asthma. Clinical Science and Molecular Medicine 1974;47:105-7.

10 Pierson WE, Bierman W, Kelley VC. A double-blind trial of corticosteroid therapy in status asthmaticus. Pediatrics 1974;54:282-8.

1 Kattan M, Gurwitz D, Levison H. Corticosteroids in status asthmaticus. J Pediatr 1980;96:596-9.

12 Tal A, Bavilski C, Yohai D, Bearman JE, Gorodischer R, Moses SW. Dexamethasone and salbutamol in the treatment of acute wheezing in infants. Pediatrics 1983;71:13-8.

13 Dabbous IA, Tkachyk JS. Stamm SJ. A double-blind study on the effects of corticosteroids in the treatment of bronchiolitis. Pediatrics 1966;37:477-84.

${ }^{14}$ Leer JE, Jr, Green JL, Heimlich EM, et al. Corticosteroid treatment in bronchiolitis. A controlled, collaborative study in 297 infants and children. Am J Dis Child 1969;117:495-503.

Correspondence to Professor A D Milner, Department of Child Health, Queen's Medical Centre, Nottingham NG7 2UH.

Received 21 August 1985 